\section{Anrea: Oncalogia/Radiaterapia}

\section{ABORTO dE FETOS ANENCEF́́liCOS}

Gustavo Nader Marta ${ }^{1 *}$, Taís Nader Marta ${ }^{2}$

Trabalho realizado no Departamento de radioterapia do centro de oncologia do Hospital Sírio-Libanês, São Paulo, SP

A saúde é um direito fundamental do homem, de eficácia imediata e auto-aplicável, é também um dever do Estado, pois o poder público está obrigado na efetivação desse direito por meio de prestações positivas essencialmente necessárias para a proteção da vida humana.

A busca do bem-estar físico, psíquico e social é o objetivo final a ser alcançado pelo direito à saúde, mas que somente se efetivará se forem disponibilizados aos cidadãos outros fatores determinantes e condicionantes, como os direitos à proteção do meio ambiente, ao saneamento, à moradia, à educação, ao bem-estar social, à seguridade social, à assistência social, ao acesso aos serviços médicos e à saúde física e psíquica.

O poder judiciário brasileiro vem autorizando, em diversas ocasiões, o abortamento nas situações de anomalia fetal grave incompatível com a vida extra-uterina. Em concordância com essa tendência, tramitam no Congresso Nacional diversos projetos de lei que visam a descriminalização do aborto em casos de anencefalia ou má formação congênita ${ }^{1}$, pois, de acordo com a Organização Mundial de Saúde, cerca de 20 milhões dos abortamentos induzidos anualmente são inseguros, sendo que 95\% desses acontecem em países em desenvolvimento. Há uma média de um abortamento inseguro para cada sete nascidos vivos. Para a América Latina, essa relação é de $1: 3^{2}$. Ademais, $13 \%$ das mortes relacionadas com a gravidez são atribuídas a complicações dessa prática, o que corresponde a cerca de 67.000 mortes anuais ${ }^{3}$. Também se associa a uma morbidade considerável, visto que uma em cada cinco mulheres que têm abortamento inseguro sofre de infecção do trato reprodutivo, o que pode levar à infertilidade 4 .

Estudos empíricos sobre o abortamento corroboram a visão de que a ilegalidade do ato nas situações de anomalia fetal grave incompatível com a vida extra-uterina acarreta execráveis consequências para a saúde feminina, não reprime tal prática e torna perpétua a desigualdade social ${ }^{4,5}$.

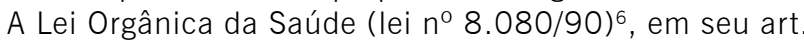
$3^{\circ}$, refere-se a vários direitos afins com o direito à saúde e à qualidade de vida, mencionando que a saúde possui características correlacionadas com a educação, a moradia, o trabalho, o saneamento básico, a renda, o meio ambiente, - lazer e o acesso aos serviços essenciais. Denota-se a necessidade do estado agir preventivamente, como legislador e como agente social, voltado para a consecução do bem comum, e incidentalmente, por meio do poder Judiciário, para a interpretação e aplicação da norma.

A saúde não pode e não deve ser conceituada como algo estático, pois faz parte de um sistema social no qual estamos inseridos e interagimos, devendo ser implementada mediante prestações positivas do Estado; está diretamente ligada ao conceito de qualidade de vida, e, para viver com dignidade em um legítimo estado democrático de direito, todo cidadão necessita ter acesso a uma vida saudável e digna e uma das visões bioéticas contemporâneas está baseada no princípio explícito de considerar e respeitar a autonomia da pessoa.

Assim, defender a possibilidade de abortamento nas situações de fetos anencefálicos não se trata de discussões acerca do direito à vida do feto, posto que a inviabilidade de vida extra-uterina é certa. Trata-se, na verdade, da discussão acerca dos direitos da gestante, direitos esses que se justificam e devem ser viabilizados face aos grandes abalos e prejuízos que suas não observâncias podem ocasionar.

\section{*Correspondência:}

Rua Adma Jafet, 91

Bela Vista

São Paulo - SP

CEP: 01308-050

Referências

1. Brasil. Projeto de lei $n^{\circ}$ 660/2007. [citado 22 set 2007]. Disponível em: http://www2.camara.gov.br/proposicoes.html.

2. World Health Organization. Unsafe abortion: global and regional estimated of incidence of mortality due to unsafe abortion with a listening of available country data. Geneve: WHO; 1996. (oms/rht/msm/97.16).

3. Organização Mundial da Saúde. OMS. Maternal mortality in 1995: estimates developed by OMS, UNCEF, UNFPA. Geneve: OMS; 2001. (oms/ rhr/01.9)

4. Monteiro MFG, Adesse I. Estimativas de aborto induzido no Brasil e grandes regiões (1992-2005). Rev Saúde Sex Reprod. 2006;(26). Disponível em: http://www.ipas.org.br/arquivos/ml2006.pdf. [ citado 12 fev 2007].

5. Brasil. Ministério da Saúde. Assistência à saúde da mulher do ciclo gravídico-puerperal: sus 1994-1997. Disponível em: http://www.saude. gov.br/programas/mulher/assist. htm\#pnatal. [citado 24 nov 1999].

6. Brasil. Presidência da República. Casa Civil. Subchefia para assuntos jurídicos. Lei n 8080 de 19 de setembro de 1990. Dispõe sobre as condições para promoção, proteção e recuperação da saúde, a organização e o funcionamento dos serviços correspondentes e dá outras providências. Disponível em: http://www.planalto.gov.br/ccivil/leis//8080.htm. [citado 5 maio 2010].

1. Médico residente do Centro de oncologia do Hospital Sírio-Libanês, São Paulo, SP

2. Especialista em direito processual e em direito constitucional pela Universidade do Sul de Santa Catarina (UNISUL); Pós-graduando strictu sensu (mestrado em direito) no Centro de pós-graduação da Instituição Toledo de Ensino em Bauru e professora do curso de direito da Faculdade anhanguera de Bauru, Bauru, SP 